\title{
Exportações e processos inovativos: um estudo para América Latina e Europa do Leste
}

\author{
Exports and innovative process: a study for Latin America and Eastern Europe
}

\author{
Marcelo José Braga Nonnenberg \\ Pontifícia Universidade Católica do Rio de Janeiro \\ Ana Paula Macedo de Avellar \\ Universidade Federal de Uberlândia
}

\begin{abstract}
The purpose of this paper is to supply evidence favoring the hypothesis that innovation contributes positively to export performance when we control for endogeneity and selection bias by means of instrumental variables and Heckman selection model, for a sample of firms for Latin America and Eastern Europe. Evidence support the existence of a behavior pattern among firms in both regions. Size, age and foreign capital share have a positive influence on export decision. There is also a positive relationship between innovation and the likelihood of firms becoming exporters. Based on Heckman procedure, we also find evidence that innovative firms are more likely to become exporters but once they become exporters, the export intensity (relative to sales) affect negatively the result, only to Latin America countries.
\end{abstract}

\section{Keywords}

exports; innovation; Latin America; East Europe; selection bias.

JEL Codes F14; O30; O31.

\section{Resumo}

O objetivo do presente artigo é fornecer evidências de que a inovação contribui para o sucesso do desempenho exportador, controlando a presença de endogeneidade e o problema de viés de seleção, por meio de variável instrumental e do modelo de seleção de Heckman, para uma amostra de firmas da América Latina e Europa do Leste. As evidências sugerem um padrão de comportamento entre as empresas, sendo que tamanho, idade e participação de capital estrangeiro influenciam positivamente na decisão de exportar dessas empresas. Quanto aos indicadores de inovação, os resultados apontam que a inovação afeta positivamente a probabilidade das empresas exportarem. Os resultados do modelo de Heckman, somente para os países da América Latina, apontam que a inovação afeta a probabilidade da empresa exportar, e influencia negativamente na intensidade das exportações em relação às vendas.

\section{Palavras-chave}

exportações; inovação; América Latina; Europa do Leste; viés de seleção.

Códigos JEL F14; O30; O31. 


\section{Introdução}

Nas últimas décadas, um dos principais motores do crescimento do comércio exterior tem sido, sem dúvida, a inovação, entendida como a incorporação de conhecimento a produtos e processos produtivos. Excluindo-se aumentos de fluxos de comércio devidos a grandes incrementos de preços de commodities, as exportações mais dinâmicas nas últimas décadas foram as de produtos com maior intensidade tecnológica. Entre 1981 e 2011, de acordo com dados do COMTRADE e adotando classificação da UNCTAD, a participação dos produtos intensivos em mão de obra ou recursos naturais ou de baixa intensidade tecnológica caiu de $19,4 \%$ para $12,6 \%$ das exportações globais, enquanto a dos produtos de média e alta intensidade tecnológica passou de $39,5 \%$ para $51,8 \%$.

Esse fato sugere, do ponto de vista microeconômico, que as firmas possuem duas estratégias básicas e complementares, caso queiram se aproveitar do maior dinamismo relativo desses mercados. Primeiro, investir diretamente na produção para exportação de produtos de maior conteúdo tecnológico. Segundo, investir em conhecimento de forma a manter e ampliar a base tecnológica de seus produtos e processos, buscando maior competitividade. Ao longo das últimas décadas, diversas firmas alteraram dramaticamente seu perfil e os setores em que atuavam, de forma a garantir o ingresso nos mercados mais dinâmicos. A líder em pesquisa e desenvolvimento Samsung foi fundada em 1938, na Coreia do Sul, como exportadora de peixe seco, legumes e frutas. Na década de 1950, passou para o ramo de seguros, ingressando no setor eletrônico apenas no final da década de 1960. A Daewoo, que durante vários anos foi uma das quatro maiores empresas da Coreia do Sul, atuando em ramos tão distintos quanto automobilística, construção civil e eletrônica (foi à falência em 1999), começou como um pequeno estaleiro.

A literatura possui amplas evidências de que as firmas exportadoras possuem características diferentes das não exportadoras. $\bigcirc$ trabalho pioneiro de Bernard e Jensen (1995) mostrou que, no caso da indústria de transformação dos Estados Unidos, no período 1976-87, as exportadoras eram maiores, mais capital intensivas, pagavam maiores salários e apresentavam maior produtividade da mão de obra quando se controlavam diversos fatores. E mostraram também que as firmas que se tornaram exportadoras apresentavam um desempenho melhor do que as não exportadoras, mes- 
mo antes de começarem a exportar. Ou seja, as "boas" empresas tinham maior probabilidade de se tornarem exportadoras do que as demais.

Posteriormente, alguns trabalhos mostraram a relação entre gastos em inovação e crescimento das exportações. Ao mesmo tempo, outros trabalhos começaram a questionar os efeitos subsequentes à exportação. Será que as firmas exportadoras teriam maior probabilidade do que as não exportadoras para inovar? Portanto, a causalidade poderia operar nos dois sentidos. Firmas mais eficientes têm mais chance de se tornarem exportadoras ou são firmas exportadoras que possuem maior probabilidade de aumentar sua eficiência? E qual o papel da inovação?

O objetivo do presente artigo é fornecer evidências de que a inovação contribui para o sucesso do desempenho exportador das empresas. A primeira questão a ser investigada neste estudo é se a inovação afeta a probabilidade da empresa exportar. Para isso, serão estimados modelos probabilísticos, com uso de variável instrumental para controlar o provável problema de endogeneidade. A segunda questão do trabalho é verificar se a inovação afeta a intensidade das exportações das empresas e, para responder a essa pergunta será utilizado o modelo de seleção de Heckman para corrigir o provável problema de viés de seleção.

A análise é conduzida com base numa amostra de firmas pesquisadas pelo Enterprise Surveys do Banco Mundial para América Latina e Europa do Leste. Este exercício empírico tenta avançar no debate sobre exportação e inovação no nível da firma, pois corrige o problema de endogeneidade e de viés de seleção, e inova em considerar a interdependência entre a decisão de exportar e a intensidade da exportação em relação às vendas das empresas.

trabalho está organizado da seguinte forma: na seção 2 , é feita uma revisão da literatura explorando a relação entre exportações, papel da inovação e desempenho da firma. A seção 3 apresenta a metodologia, e a seção 4 apresenta os dados e a análise da estatística descritiva. A seção 5 discute os resultados econométricos. As conclusões são resumidas na última seção.

\section{Revisão da literatura}

A teoria evolucionária ${ }^{1}$ enfatizou a relação entre inovação e exportações há

1 Alguns esforços teóricos e empíricos vêm sendo desenvolvidos com intuito de estabelecer conexões entre a teoria evolucionária e a teoria dos modelos de crescimento "orientados pela 
vários anos, principalmente pelo impacto do esforço inovativo sobre a competitividade das firmas. Desse modo, diversos trabalhos empíricos mostraram evidências nesse sentido (Fagerberg, 1988a). Basicamente, há dois tipos de perguntas. A primeira é se a firma exporta porque inova ou inova porque exporta. Outra pergunta é se a firma aprende com a exportação (learning by exporting) ou se há viés de seleção. Ou seja, se a produtividade aumenta porque exporta ou se são as mais produtivas que se tornam exportadoras.

Inspirados nos trabalhos pioneiros de Vernon (1966) e Posner (1961), surgiram estudos relacionando o desempenho exportador e a inovação a partir da década de 1980. A hipótese é que o esforço em inovação, medido de diversas formas, teria um impacto positivo sobre o crescimento das exportações. Nesse sentido, esses trabalhos buscavam refutar parcialmente as principais teorias sobre determinantes do comércio exterior, como o modelo de Hecksher-Ohlin e os primeiros trabalhos que introduziam a concorrência monopolística e a presença de economias de escala (Krugman, 1979). A inovação teria efeitos positivos sobre o comércio por meio de três canais: (a) desenvolvimento de novos produtos; (b) melhoria da qualidade dos produtos existentes; e (c) redução de custos por inovações de processo, com aumento da competitividade (Posner, 1961). Na década de 1960 (e mesmo nas décadas seguintes) a inovação estava concentrada em poucos países ricos, o que gerava efeitos de escala, aumentando a produção apenas nesses países, desta forma, incentivando o comércio.

Alguns estudos [Pavitt; Soete (1980) e outros revistos em OCDE (1980)] procuraram medir o impacto de medidas de insumo de $\mathrm{P} \& \mathrm{D}$ sobre o comércio exterior. Soete (1981) busca inovar utilizando uma medida de resultado de $\mathrm{P} \& \mathrm{D}$, o número de patentes. É feito um estudo de cross-section com os 22 países da OCDE para 1977 para 40 setores industriais. O estudo utiliza como variável dependente a participação das exportações de cada país nas exportações totais da OCDE e como variáveis independentes população, PIB, razão capital/produto, distância e número de patentes depositadas nos EUA. Todas as variáveis são referentes a 1977, exceto patentes, que se referem à média de 1963-77. Das 40 equações estimadas, são encontrados

demanda". Entre os resultados encontrados por esses estudos verifica-se que uma maior intensidade tecnológica dos produtos comercializados pelas empresas possibilita mudanças nas elasticidades-renda do comércio internacional, ou seja, maior elasticidade-renda da demanda por exportações. Assim, consequentemente, o efeito se dá sobre a diminuição da restrição externa e sobre o maior crescimento econômico de longo prazo (Fagerberg, 1988b; Missio; Gabriel, 2014). 
resultados significativos para a variável de medida do esforço inovativo em 28 delas. Note-se, entretanto, que o número de observações (22) em cada equação é muito baixo para permitir inferências mais precisas.

Seguindo essa linha de investigação, vários outros trabalhos foram publicados nos anos subsequentes focando sempre no impacto da inovação sobre o desempenho das exportações, brutas ou líquidas. Por exemplo, Fagerberg (1988a) testa um modelo com dados para 15 países industrializados no período 1960-83 e conclui que entre os principais fatores que influenciam a competitividade externa de um país estão os índices de tecnologia e a capacidade de competir na logística. Greenhalgh (1990) utiliza dados elaborados pelo SPRU da Universidade de Sussex para o Reino Unido para o período 1954-81 que contêm o número de inovações por indústria e por ano. Com base nessa variável e num conjunto de variáveis de controle, é testada a influência da inovação sobre as exportações líquidas de 31 setores industriais. As evidências não são muito conclusivas na medida em que encontram resultados significativos e positivos para apenas 9 setores. Além disso, encontra resultados negativos e significativos (pois são setores com redução das exportações líquidas ou com aumento da penetração das importações) para mais 6 setores. Sterlacchini (1999) investiga o comportamento de 4005 empresas em uma região da Itália por meio da estimação de um modelo probabilístico. $O$ autor evidencia que a probabilidade da empresa tornar-se uma exportadora é afetada positivamente pelo seu tamanho e pelas atividades inovativas realizadas.

Resultados significativos também são obtidos por Amable e Verspagen (1995), que trabalham com amostra de cinco países industrializados e 18 setores industriais. Medindo-se o desempenho externo como a participação de mercado desses países e a inovação como número de patentes depositadas nos EUA, são encontrados resultados positivos e significativos para o conjunto da amostra e em 11 dos 18 setores. Wakelin (1998) utiliza amostra de fluxos bilaterais de comércio para 9 países da OECD e 22 setores da indústria de transformação. Ela inova ao construir indicadores relativos de inovação, de salário para cada par de país e cada setor. A variável dependente também é construída como exportação relativa por pares de países e setores, e os dados são referentes ao período 1980-88. A inovação é medida por gastos em $\mathrm{P} \& \mathrm{D}$ e número de patentes nos EUA. Os resultados indicam que há grandes divergências entre os países e que a variável "patentes" mede melhor o esforço de inovação e sua influência sobre as ex- 
portações, com coeficientes significativos e com sinal correto para a maioria dos setores e para todos os que são normalmente classificados como de alta intensidade tecnológica, como eletrônica, farmacêutica, instrumentos.

Mais recentemente, contudo, a literatura empírica começou a questionar a relação de causalidade entre inovação, produtividade e crescimento das exportações. Começando com o trabalho de Bernard e Jensen (1995), passou-se a discutir se as empresas exportadoras apresentam melhor desempenho em termos de produtividade, emprego e salários porque exportam (learning by exporting) ou se são as melhores empresas que se tornam exportadoras (autosseleção). Inicialmente, a questão da inovação não estava no debate, sendo introduzida posteriormente. Os autores utilizam uma amostra de 56 mil empresas retirada da Pesquisa Anual de Empresas da Indústria de Transformação dos Estados Unidos para os anos entre 1976 e 1987, separando exportadoras de não exportadoras. As conclusões são que, primeiro, as exportadoras são maiores, pagam melhores salários, têm maiores razões capital/trabalho e empregam mais do que as não exportadoras. Mas a análise ao longo do tempo revela que são as melhores empresas que se tornam exportadoras e não o contrário, ou seja, o desempenho das exportadoras não se altera significativamente ao ingressarem no comércio internacional. Trabalho adicional dos mesmos autores (Bernard; Jensen, 1999) confirma que são as firmas com melhor desempenho que se tornam exportadoras mas que, uma vez que se tornam exportadoras, sua produtividade não cresce significativamente mais do que a das não exportadoras. Diversos outros trabalhos confirmam tais resultados, em maior ou menor grau (Clerides; Lach; Tybout, 1998; Bernard; Jensen, 2004; Kim; Gopinath; Kim, 2009).

No entanto, vários autores encontraram resultados diferentes, ainda que praticamente todos concordem com a hipótese de autosseleção das melhores empresas. Por exemplo, Trofimenko (2008), Martins e Yang (2009) e Anderson e Lööf (2009) aceitam a hipótese de learning by exporting. Por sua vez, Damijan e Kostevc (2006) encontram evidências não conclusivas a favor dessa hipótese. Greenaway e Kneller (2007) inovam ao desenhar um experimento com um grupo-alvo e um grupo de controle, que é utilizado com uma amostra de firmas manufatureiras do Reino Unido entre 1989 e 1998. Eles encontram como resultado que o crescimento da produtividade das empresas exportadoras é maior após a entrada no mercado internacional do que o das empresas não exportadoras, mas que a intensidade desse fenômeno varia de acordo com os setores. 
Diversos trabalhos recentes voltaram a analisar a influência direta da inovação sobre o desempenho dos países no comércio exterior, normalmente em conjunto com o exame da hipótese de learning by exporting. A ideia central é a de que a firma que passa a ser exportadora (ainda que prevaleça a hipótese de autosseleção) aumente sua produtividade principalmente ao incorporar conhecimento e realize investimentos que a tornem capaz de absorver esse conhecimento. Sanyal (2004) considera que há fortes evidências de que a intensidade tecnológica e as oportunidades tecnológicas influenciam o desempenho comercial bilateral, ao analisar países da OCDE. Girma, Göorg e Hanley (2008) encontram esse mesmo resultado para o caso da Irlanda, mas não para o Reino Unido. Liu e Buck (2007), estudando empresas chinesas, também concordam com essa conclusão, entretanto, enfatizam a importância dos investimentos necessários para o aumento da capacidade de absorção. Já Beise-Zee e Rammer (2006) ressaltam o impacto do mercado local e de suas características para o processo de inovação e, assim, para o sucesso das firmas ao exportar.

Aw, Roberts e Winston (2007 e 2008) analisam dados de firmas da indústria eletrônica de Taiwan para 1986, 1991 e 1996 e constroem indicadores de produtividade total de fatores. Firmas mais produtivas têm maior probabilidade de se tornarem exportadoras, ao mesmo tempo em que as firmas que se tornam exportadoras apresentam maior probabilidade de virem a aumentar sua produtividade, e esse efeito é tão maior quanto maiores forem os dispêndios em $\mathrm{P} \& \mathrm{D}$. Ou seja, o cenário projetado indica que as firmas que mais investiram na sua base de conhecimento aumentaram mais sua produtividade o que, por sua vez, permite maiores investimentos em inovação. Esses resultados são confirmados por Aw, Roberts e Xu (2009) com dados também para a indústria eletrônica de Taiwan para o período 2000-2004. Harris e Li (2009) consideram que $\mathrm{P} \& \mathrm{D}$ é importante para a firma passar a ser exportadora, mas investimentos adicionais apresentam pouco impacto sobre o esforço exportador.

\section{Metodologia}

A primeira etapa da estratégia empírica deste trabalho consiste na especificação e estimação de modelos probabilísticos para investigar a rela- 
ção entre inovação e probabilidade de exportar (Cameron; Trivedi, 2010; Wooldridge, 2010).

Considere a variável binária observável $y_{i}$ e a variável contínua não observável (latente) $y_{i}^{*}$, a qual satisfaz o seguinte modelo:

$$
y_{i}^{*}=\mathrm{x}_{i}^{\prime} \beta+u_{i}
$$

em que $x_{i}$ é um vetor coluna $k x 1$ e $\beta$ é um vetor coluna $k x 1$. Embora $y_{i}^{*}$ não seja observável, pode-se observar:

$$
y_{i}=\left\{\begin{array}{l}
1, \operatorname{sey}_{i}^{*}>0 \\
0, \operatorname{sey}_{i}^{*} \leq 0
\end{array}\right.
$$

Dados os modelos (1) e (2) para a variável latente, tem-se:

$$
\begin{aligned}
& \operatorname{Pr}\left(y_{i}=1\right)=\operatorname{Pr}\left(\mathrm{x}_{i}^{\prime} \beta+u_{i}>0\right) \\
& \operatorname{Pr}\left(y_{i}=1\right)=\operatorname{Pr}\left(-u_{i}<\mathrm{x}_{i}^{\prime} \beta\right) \\
& \operatorname{Pr}\left(y_{i}=1\right)=F\left(\mathrm{x}_{i}^{\prime} \beta\right)
\end{aligned}
$$

onde $F\left(\right.$.) é uma função de distribuição cumulativa de $-u_{i}$. Se $u_{i}$ é normalmente distribuído, tem-se o modelo probit.

Conforme Ganotakis e Love (2011), Harris e Li (2009) e Lachenmaier e Woessmann (2006) as variáveis de inovação são potencialmente endógenas no modelo probabilístico, o que torna necessário um procedimento de variáveis instrumentais.

Como no trabalho são utilizadas duas variáveis de inovação, uma contínua e uma discreta, para o modelo probabilístico cuja variável de inovação é contínua, utiliza-se o modelo IV Probit, e para o modelo probabilístico cuja variável de inovação é discreta, utiliza-se o modelo Bi Probit. O modelo IV Probit ajusta modelos com variável binária e regressores endógenos contínuos, enquanto que o modelo Bi Probit considera dois resultados binários, potencialmente relacionados.

A estrutura formal do modelo IV Probit é descrita por:

$$
\begin{aligned}
& y_{1 i}^{*}=y_{2 i} \beta+\mathrm{x}_{1 i}^{\prime} \gamma+u_{i} \\
& y_{2 i}=\mathrm{x}_{1 i}^{\prime} \pi_{1}+\mathrm{x}_{2 i}^{\prime} \pi_{2}+v_{i}
\end{aligned}
$$


em que $y_{2 i}$ é uma variável endógena, $x_{1 i}$ é um vetor coluna $k_{1} \mathrm{x} 1$ de variáveis exógenas, $x_{2 i}$ é um vetor coluna $k_{2} \times 1$ de instrumentos adicionais, $\beta$ e $\gamma$ são vetores de parâmetros estruturais e $\pi_{1}$ e $\pi_{2}$ são vetores de parâmetros em forma reduzida. Embora $y_{1 i}^{*}$ não seja observável, pode-se observar:

$$
y_{1 i}=\left\{\begin{array}{l}
1, \operatorname{sey} y_{1 i}^{*}>0 \\
0, \operatorname{sey}_{1 i}^{*} \leq 0
\end{array}\right.
$$

Um teste Wald é utilizado para testar a hipótese nula de que a variável instrumentalizada é exógena.

No modelo Bi Probit os dois resultados binários são determinados pelas duas variáveis não observáveis (latentes):

$$
\begin{aligned}
& y_{1 i}^{*}=\mathrm{x}_{1 i}^{\prime} \beta_{1}+\varepsilon_{1 i} \\
& y_{2 i}^{*}=\mathrm{x}_{2 i}^{\prime} \beta_{2}+\varepsilon_{2 i}
\end{aligned}
$$

onde $x_{1 i}$ é um vetor coluna $k_{1} \mathrm{x} 1, x_{2 i}$ é um vetor coluna $k_{2} \mathrm{x} 1, \beta_{1}$ é um vetor coluna $k_{1} \times 1$ e $\beta_{2}$ é um vetor coluna $k_{2} \times 1$. Os erros $\varepsilon_{1 i}$ e $\varepsilon_{2 i}$ são normalmente distribuídos com média 0 , variância 1 e correlação $\rho$. Os dois resultados binários observáveis são:

$$
\begin{aligned}
& y_{1 i}=\left\{\begin{array}{l}
1, \text { sey } y_{1 i}^{*}>0 \\
0, \text { sey } y_{1 i}^{*} \leq 0
\end{array}\right. \\
& y_{2 i}=\left\{\begin{array}{l}
1, \operatorname{sey} y_{2 i}^{*}>0 \\
0, \text { sey } y_{2 i}^{*} \leq 0
\end{array}\right.
\end{aligned}
$$

O modelo colapsa para dois modelos probit distintos para $y_{1}$ e $y_{2}$ se $\rho=0$. Um teste Wald é utilizado para testar a hipótese nula de que $\rho=0$.

A segunda etapa da estratégia empírica adotada neste trabalho consiste na especificação e estimação do modelo de seleção de Heckman com o objetivo de investigar a relação entre inovação e intensidade de exportação (Cameron; Trivedi, 2010; Wooldridge, 2010; Heckman, 1979).

Conforme Ganotakis e Love (2011), Harris e Li (2009) e Correa, Dayoub e Francisco (2007), a utilização do modelo de seleção é necessária, pois a variável de resultado intensidade de exportação $\left(y_{2 i}\right)$ só é observada 
se algum critério, definido em termos da propensão a exportar $\left(y_{1 i}\right)$, for cumprido.

O modelo de seleção de Heckman compreende uma equação de seleção para $y_{1 i}$, onde:

$$
y_{1 i}=\left\{\begin{array}{l}
1, \operatorname{sey} y_{1 i}^{*}>0 \\
0, \operatorname{se} y_{1 i}^{*} \leq 0
\end{array}\right.
$$

E uma equação de resultado para $y_{2 i}$, onde:

$$
y_{2 i}=\left\{\begin{array}{l}
y_{2 i}^{*}, \text { sey } y_{1 i}^{*}>0 \\
-, \text { sey } y_{1 i}^{*} \leq 0
\end{array}\right.
$$

Nesse caso $y_{2 i}$ é observado somente quando $y_{1 i}^{*}>0$ e não assume valor quando $y_{1 i}^{*} \leq 0$. A versão clássica do modelo é linear com erros aditivos, então:

$$
\begin{aligned}
& y_{1 i}^{*}=\mathrm{x}_{1 i}^{\prime} \beta_{1}+\varepsilon_{1 i} \\
& y_{2 i}^{*}=\mathrm{x}_{2 i}^{\prime} \beta_{2}+\varepsilon_{2 i}
\end{aligned}
$$

A correlação entre $\varepsilon_{1 i}$ e $\varepsilon_{1 i}$ é $\rho$. Se $\rho=0$ não existe viés de seleção, e se $\rho \neq 0$ existe viés de seleção. Um teste Wald testa a hipótese nula de que $\rho=0$.

\section{Dados e caracterização das empresas}

Para a realização da análise empírica, o trabalho utilizou-se da base de dados do Banco Mundial (Enterprises Surveys) para uma amostra de empresas da América Latina e Europa do Leste. Enterprises Survey é um levantamento no nível da firma de uma amostra representativa do setor privado da economia. As pesquisas envolveram um amplo conjunto de temas sobre ambiente de negócios, incluindo as características da empresa, a participação de gênero, acesso ao financiamento, as vendas anuais, a composição da força de trabalho, licenciamento, infraestrutura, comércio, crime, concorrência, inovação e tecnologia, e medidas de desempenho. $O$ modo de coleta de dados é por meio de entrevistas. Essas pesquisas têm sido 
realizadas desde 2002 por diferentes unidades dentro do Banco Mundial. Contudo, desde 2005-06, a maioria dos esforços de coleta de dados tem sido centralizada na Enterprise Analysis Unit. O conjunto de dados de cada país e toda a documentação relevante das pesquisas estão disponíveis ao público na internet. ${ }^{2}$ As pesquisas são geralmente realizadas em cooperação com as organizações empresariais e agências governamentais que promovem a criação de emprego e crescimento econômico, garantindo a confidencialidade dos entrevistados e das informações.

Tabela 1 Descrição das variáveis

\begin{tabular}{|c|c|c|c|}
\hline Grupos & Variáveis & Descrição & $\begin{array}{r}\text { Sinal } \\
\text { Esperado }\end{array}$ \\
\hline \multirow{2}{*}{$\begin{array}{l}\text { Indica- } \\
\text { dores Ex- } \\
\text { portação }\end{array}$} & Exporta & Dummy empresa exporta diretamente & \\
\hline & $\begin{array}{l}\text { Intensidade } \\
\text { Exporta }\end{array}$ & $\%$ receita de vendas com exportação & \\
\hline \multirow{8}{*}{$\begin{array}{l}\text { Caracte- } \\
\text { rísticas }\end{array}$} & PO & Número do Pessoal Ocupado & + \\
\hline & $\mathrm{PO}^{2}$ & Pessoal Ocupado ao Quadrado & - \\
\hline & CapEstrangeiro & Dummy empresa mais de $10 \%$ de capital estrangeiro & + \\
\hline & Idade & Anos de fundação da empresa & + \\
\hline & Multi-Planta & Dummy empresa possui mais de uma planta produtiva & + \\
\hline & Pequena Empresa & Dummy empresa com 0-24 colaboradores & - \\
\hline & Média Empresa & Dummy empresa com 25-99 colaboradores & - \\
\hline & Grande Empresa & Dummy empresa com mais de 100 colaboradores & + \\
\hline \multirow{10}{*}{$\begin{array}{l}\text { Capaci- } \\
\text { tação }\end{array}$} & Qualidade & Dummy empresa possui certificado de qualidade & + \\
\hline & TecnLicenciada & Dummy empresa licencia tecnologia estrangeira & + \\
\hline & Skill & $\begin{array}{r}\text { Número de PO com } 3^{\circ} \text { Grau completo atuante } \\
\text { na produção }\end{array}$ & + \\
\hline & Treinamento & Número de $\mathrm{PO}$ que realiza treinamento & + \\
\hline & Treinamento2 & Dummy empresa realiza treinamento aos funcion. & + \\
\hline & Alta Tecnologia & Dummy empresa de Máq.e Equip. e Eletrônicos & + \\
\hline & Apoio Governo & $\begin{array}{r}\text { Dummy empresa recebeu apoio do governo } \\
\text { nos últimos } 3 \text { anos }\end{array}$ & + \\
\hline & $\mathrm{UCl}$ & \% Utilização da Capacidade Instalada & + \\
\hline & Internet & Dummy empresa se comunica por e-mail website & + \\
\hline & Insumo Importado & Dummy empresa importa insumos & + \\
\hline
\end{tabular}

(continua) 
Tabela 1 (continuação)

\begin{tabular}{l|l|r|r}
\hline Grupos & Variáveis & Descrição & $\begin{array}{r}\text { Sinal } \\
\text { Esperado }\end{array}$ \\
\hline $\begin{array}{l}\text { Indica- } \\
\text { dores de } \\
\text { Inovação }\end{array}$ & Inova & Dummy empresa introduziu novos produtos & + \\
\cline { 2 - 5 } & Intensidade Inova & Número de novos produtimos 3 anos & + nos últimos 3 anos \\
\cline { 2 - 5 } & PeD & Gasto PeD & + \\
\cline { 2 - 5 } & Intensidade PeD & Gasto PeD/Receita & + \\
\hline
\end{tabular}

Fonte: Elaboração própria.

As variáveis utilizadas neste estudo estão organizadas em quatro grupos e descritas na Tabela 1, assim como o sinal que se espera encontrar em cada uma das variáveis. No primeiro grupo organizam-se os indicadores de exportação, no segundo estão as características das firmas, no terceiro grupo estão os indicadores de capacitação e, no quarto, os indicadores de inovação.

As variáveis selecionadas foram as que estavam disponíveis para as amostras de ambas as regiões, mas parecem fornecer um quadro razoavelmente amplo das características das empresas e de variáveis relacionadas com o processo de inovação. São semelhantes também às utilizadas em outros estudos (Ganotakis; Love, 2011; Correa; Dayoub; Francisco, 2007; Harris; Li, 2009). De forma geral, espera-se que a utilização de insumos ligados à inovação ou à existência de inovação favoreça as exportações das empresas nas duas regiões.

A amostra da América Latina é constituída pelas empresas dos seguintes países: Argentina, Brasil, Chile, Colômbia, Costa Rica, México, Peru e Venezuela. Os dados apresentados nessa base correspondem ao período de 2006 a 2008. ${ }^{3}$ Para a Europa do Leste as empresas analisadas foram as referentes aos países: Belarus, Bulgária, Eslováquia, Hungria, Lituânia, Polônia, República Tcheca, Romênia, Rússia e Ucrânia, para o período de 2007 a 2009. A seleção desses países baseou-se na relevância econômica e no comércio internacional de cada país na região a qual pertence. O número de firmas de cada região e de cada país está apresentado na Tabela 2.

Quanto ao recorte setorial (ver Tabela 3), é importante destacar que foram retiradas da amostra as empresas que atuavam no setor de servi-

3 Os dados para as firmas do Brasil foram retirados do questionário realizado em 2003. 
ços, mantendo-se na base de dados apenas empresas que atuavam em 13 setores divididos em setor industrial (manufatura) e comercial (atacado e varejo).

Tabela 2 Número de firmas por região e país

\begin{tabular}{lr|l|r}
\hline América Latina & & Europa do Leste & \\
\hline País & No Observações & País & No Observações \\
\hline Argentina & 964 & Bielorrúsia & 230 \\
\hline Brasil & 1.637 & Bulgária & 223 \\
\hline Chile & 962 & Eslováquia & 217 \\
\hline Colômbia & 868 & Hungria & 227 \\
\hline Costa Rica & 445 & Lituânia & 201 \\
\hline México & 1.298 & Polônia & 336 \\
\hline Peru & 933 & República Tcheca & 195 \\
\hline Venezuela & 238 & Romênia & 399 \\
\hline & & Rússia & 897 \\
\hline & & Ucrânia & 749 \\
\hline Total & 7.327 & Total & 3.674 \\
\hline Total geral & & 11.001 \\
\hline
\end{tabular}

Fonte: Elaboração Própria. Dados: Banco Mundial.

Nota-se, pela Tabela 3, que há um padrão relativamente semelhante na distribuição setorial entre as duas regiões quando se examina o total de empresas. Nas duas regiões (América Latina e Europa do Leste), os setores industriais que concentram o maior número de empresas são Alimentos (14.9\% e $12.3 \%$ ) e Vestuário (13.8\% e 10.7\%), além de Outras Manufaturas (16.8\% e $11.5 \%)$. Deve-se destacar também a grande participação de empresas comerciais do segmento de Varejo, representando $11.5 \%$ das empresas dos países da América Latina e 29\% das empresas dos países da Europa do Leste.

Quando se analisa o perfil setorial entre exportadoras e não exportadoras, observa-se alguma diferença entre as regiões. De toda forma, o número de empresas exportadoras é relativamente menor em ambas as regiões. Contudo, para os países da América Latina, alguns setores apresentam comportamento distinto, sendo o número de exportadoras maior que o das não exportadoras: Metais Básicos e Plásticos. Esse mesmo fato também ocorre no caso dos países da Europa do Leste para os setores de Eletrônicos, Metais Básicos e Têxtil. 
Tabela 3 Distribuição setorial das firmas da América Latina e Europa do Leste

\begin{tabular}{l|r|r|r|r|r|r|r|r}
\hline Variáveis & \multicolumn{4}{r}{ América Latina } & \multicolumn{4}{|r}{ Europa do Leste } \\
\cline { 2 - 11 } & Exporta & $\begin{array}{r}\text { Não } \\
\text { Exporta }\end{array}$ & Total & $\%$ & Exporta & $\begin{array}{r}\text { Não } \\
\text { Exporta }\end{array}$ & Total & $\%$ \\
\hline Alimentos & 379 & 713 & 1092 & $14.9 \%$ & 95 & 356 & 451 & $12.3 \%$ \\
\hline Eletrônicos & 57 & 72 & 129 & $1.8 \%$ & 28 & 22 & 50 & $1.4 \%$ \\
\hline Química & 349 & 378 & 727 & $9.9 \%$ & 61 & 80 & 141 & $3.9 \%$ \\
\hline Metais básicos & 36 & 20 & 56 & $0.8 \%$ & 26 & 13 & 39 & $1.0 \%$ \\
\hline Produtos de metais & 249 & 391 & 640 & $8.8 \%$ & 86 & 174 & 260 & $7.1 \%$ \\
\hline Produtos não metal & 44 & 78 & 122 & $1.7 \%$ & 17 & 52 & 69 & $1.9 \%$ \\
\hline Plásticos & 192 & 182 & 374 & $5.1 \%$ & 35 & 45 & 80 & $2.1 \%$ \\
\hline Máquinas e equip. & 257 & 294 & 551 & $7.5 \%$ & 161 & 187 & 348 & $9.5 \%$ \\
\hline Têxtil & 161 & 208 & 369 & $5.0 \%$ & 35 & 24 & 59 & $1.6 \%$ \\
\hline Vestuário & 274 & 737 & 1011 & $13.8 \%$ & 102 & 292 & 394 & $10.7 \%$ \\
\hline Outras manufaturas & 417 & 815 & 1232 & $16.8 \%$ & 159 & 261 & 420 & $11.5 \%$ \\
\hline Comércio - atacado & 42 & 141 & 183 & $2.5 \%$ & 83 & 215 & 298 & $8.1 \%$ \\
\hline Comércio - varejo & 75 & 766 & 841 & $11.5 \%$ & 124 & 941 & 1065 & $29.0 \%$ \\
\hline Total & 2532 & 4795 & 7327 & $100 . \%$ & 1012 & 2662 & 3674 & $100 \%$ \\
\hline
\end{tabular}

Fonte: Elaboração Própria. Dados: Banco Mundial.

Nota (1): "Outras Manufaturas" incluem as atividades manufatureiras de madeira, papel e celulose, automóveis e autopeças, entre outras.

Quanto ao perfil das firmas analisadas, por país e por região, as Tabelas 4 e 5 evidenciam importantes características, ressaltando indicadores de inovação, de capacitação e do perfil exportador.

Uma análise geral dos indicadores apresentados na Tabela 4 indica que as exportadoras são, em média, mais qualificadas do que as não exportadoras. Pode-se afirmar que as exportadoras são mais velhas, são mais intensivas em P\&D e no desenvolvimento de novos produtos (Intensidade Inovação), são maiores, possuem um percentual do pessoal ocupado com treinamento superior às não exportadoras, utilizam-se de um maior percentual de insumos importados e apresentam uma maior utilização de capacidade instalada. Destaca-se ainda que apenas no indicador de qualificação de pessoal (Skill), que indica o percentual do pessoal ocupado na produção que possui $3^{\circ}$ grau completo, as não exportadoras apresentam, para as duas regiões, percentuais superiores às exportadoras. 
Tabela 4 Características das firmas da América Latina e Europa do Leste (média e desvio padrão)

\begin{tabular}{lrrrr}
\hline Variáveis & & América Latina & & Europa do Leste \\
\hline & Exporta & Não Exporta & Exporta & Não Exporta \\
\cline { 2 - 5 } Idade (anos) & 30.5 & 22.61 & 20.14 & 15.07 \\
\cline { 2 - 5 } Intensidade & $(22.6659)$ & $(18.1046)$ & $(23.0618)$ & $(14.6785)$ \\
exportação (\%) & 28.52 & - & 39.67 & - \\
\hline Intensidade & $(29.9878)$ & - & $(33.7959)$ & - \\
inovação (\%) & 14.5 & 10.49 & 20.19 & 14.96 \\
\hline Intensidade & $(21.12)$ & $(20.62)$ & $(24.337)$ & $(22.6902)$ \\
P\&D (\%) & 0.0121 & 0.009 & 0.010 & 0.009 \\
\hline Pessoal ocupado & $(0.0409)$ & $(0.0397)$ & $(0.0501)$ & $(0.2313)$ \\
(número) & 298.98 & 122.59 & 263.32 & 92.57 \\
\hline Skill & $(984.628)$ & $(1498.93)$ & $(632.668)$ & $(413.765)$ \\
\hline \% PO com & 0.53 & 0.54 & 0.76 & 0.81 \\
\hline treinamento & $(0.3437)$ & $(0.3655)$ & $(0.2524)$ & $(0.2460)$ \\
\hline Insumo & 37.02 & 17.91 & 42.87 & 35.77 \\
importado (\%) & $(42.4749)$ & $(35.3488)$ & $(36.2077)$ & $(36.5905)$ \\
\hline UCl (\%) & 32.83 & 23.55 & 37.98 & 21.93 \\
\hline & $(31.1924)$ & $(30.6720)$ & $(35.824)$ & $(32.4333)$ \\
\hline & 73.27 & 71.51 & 80.17 & 78.54 \\
\hline & $(18.3728)$ & $(19.2845)$ & $(19.2092)$ & $(21.5110)$ \\
\hline
\end{tabular}

Fonte: Elaboração Própria. Dados: Banco Mundial.

Nota: Desvio padrão entre parênteses.

Quanto às especificidades regionais, as empresas da América Latina são mais velhas, têm menor intensidade de exportação e de inovação apesar de apresentarem idêntica intensidade de $\mathrm{P} \& \mathrm{D}$ em comparação com as empresas da Europa do Leste. Apresentam tamanhos semelhantes, mas possuem menor qualificação de pessoal, bem como menor percentual de pessoal ocupado com treinamento, em relação às empresas da Europa do Leste.

Pela Tabela 5, pode-se observar que a maioria das firmas em ambas as regiões é constituída por não exportadoras. Entre as exportadoras, o percentual de empresas inovadoras é maior em ambas as regiões, bem como o gasto relativo em $\mathrm{P} \& \mathrm{D}$. Apenas um pequeno número de empresas pode ser classificado em setores altamente intensivos em tecnologia. 
Vale ressaltar também que, nas duas regiões, as empresas exportadoras têm uma maior participação de capital estrangeiro, fazem maior uso de tecnologia licenciada, e recebem apoio do governo em maior proporção.

Tabela 5 Características das firmas da América Latina e Europa do Leste (variáveis binárias - número e participação \%)

\begin{tabular}{l|r|r|r|r|r|r|r|r}
\hline \multirow{2}{*}{ Variáveis } & \multicolumn{4}{|c|}{ América Latina } & \multicolumn{3}{|r}{ Europa do Leste } \\
\cline { 2 - 10 } & Exporta & $\%$ & $\begin{array}{r}\text { Não } \\
\text { Exporta }\end{array}$ & $\%$ & Exporta & $\begin{array}{r}\text { Não } \\
\text { Exporta }\end{array}$ & $\%$ \\
\hline Alta tecnologia & 314 & $12.40 \%$ & 366 & $7.63 \%$ & 189 & $18.68 \%$ & 209 & $7.85 \%$ \\
\hline Capital estrangeiro & 535 & $21.16 \%$ & 213 & $4.45 \%$ & 207 & $21.12 \%$ & 148 & $5.67 \%$ \\
\hline Certificado qualidade & 1286 & $51.48 \%$ & 776 & $16.45 \%$ & 344 & $34.26 \%$ & 263 & $9.97 \%$ \\
\hline Tecnologia licenciada & 514 & $21.52 \%$ & 306 & $8.06 \%$ & 206 & $28.89 \%$ & 210 & $17.62 \%$ \\
\hline Inovadora & 1599 & $66.93 \%$ & 2014 & $53.07 \%$ & 751 & $74.65 \%$ & 1480 & $56.00 \%$ \\
\hline P\&D & 1539 & $64.37 \%$ & 1488 & $39.18 \%$ & 406 & $40.72 \%$ & 487 & $18.54 \%$ \\
\hline Treinamento & 1990 & $78.72 \%$ & 2594 & $54.31 \%$ & 341 & $33.70 \%$ & 325 & $12.21 \%$ \\
\hline Multi-planta & 1022 & $40.36 \%$ & 1837 & $38.31 \%$ & 150 & $14.82 \%$ & 291 & $10.93 \%$ \\
\hline Internet & 2518 & $99.45 \%$ & 4424 & $92.26 \%$ & 937 & $93.14 \%$ & 2205 & $83.33 \%$ \\
\hline Apoio do governo & 297 & $15.72 \%$ & 216 & $8.11 \%$ & 178 & $17.91 \%$ & 181 & $6.92 \%$ \\
\hline Total & 2532 & & 4795 & & 1012 & & 2662 & \\
\hline
\end{tabular}

Fonte: Elaboração Própria. Dados: Banco Mundial.

No que se refere ao porte das firmas analisadas no estudo, a Tabela 6 apresenta a distribuição das firmas das duas amostras de região considerando o recorte pequena (0-24 funcionários), média (25-99 funcionários) e grande empresa (mais de 100 funcionários).

Tabela 6 Porte das firmas da América Latina e Europa do Leste (número e \%)

\begin{tabular}{|c|c|c|c|c|c|c|c|c|}
\hline \multirow[t]{2}{*}{ Porte } & \multicolumn{4}{|c|}{ América Latina } & \multicolumn{4}{|c|}{ Europa do Leste } \\
\hline & Exporta & $\%$ & $\begin{array}{r}\text { Não } \\
\text { Exporta }\end{array}$ & $\%$ & Exporta & $\%$ & $\begin{array}{r}\text { Não } \\
\text { Exporta }\end{array}$ & $\%$ \\
\hline Pequena & 389 & $15.36 \%$ & 2414 & $50.34 \%$ & 192 & $18.97 \%$ & 1329 & $49.92 \%$ \\
\hline Média & 840 & $33.18 \%$ & 1573 & $32.81 \%$ & 296 & $29.25 \%$ & 751 & $28.21 \%$ \\
\hline Grande & 1303 & $51.46 \%$ & 808 & $16.85 \%$ & 524 & $51.78 \%$ & 582 & $21.86 \%$ \\
\hline Total & 2532 & & 4795 & & 1012 & & 2662 & \\
\hline
\end{tabular}

Fonte: Elaboração Própria. Dados: Banco Mundial. 
Verifica-se um predomínio das grandes empresas entre as exportadoras e de pequenas empresas entre as não exportadoras, o que é um resultado esperado. Em ambas as regiões, as empresas de grande porte (mais de 100 funcionários) representam mais da metade das empresas exportadoras (51.46\% na América Latina e 51.78\% na Europa do Leste).

A partir desse quadro, a próxima seção se centrará na apresentação e discussão dos resultados dos modelos econométricos estimados.

\section{Análise de resultados}

As Tabelas 7 e 8 apresentam os resultados das estimações econométricas desenvolvidas neste estudo. ${ }^{4} \mathrm{Na}$ Tabela $7,{ }^{5}$ as colunas 1, 2, 5 e 6 apresentam, respectivamente, os resultados do modelo probit para as amostras de empresas da América Latina e Europa do Leste, com o objetivo de testar o efeito da inovação na probabilidade das empresas exportarem. A variável dependente é binária, assumindo valor 1 se a empresa exporta e valor 0 se a empresa não exporta. As variáveis independentes são: i) características da empresa: pessoal ocupado, pessoal ocupado ao quadrado, idade da empresa, participação de capital estrangeiro; ii) capacitação da empresa: qualidade, uso de tecnologia licenciada, treinamento e uso de insumos importados; iii) indicadores de inovação: inova (colunas 1 e 5), uma variável binária, que assume valor 1 se a empresa desenvolveu um novo produto e valor 0 , caso contrário; ou intensidade inova (colunas 2 e 6), uma variável contínua, que descreve o número de novos produtos lançados pela empresa.

Os resultados dos modelos probabilísticos, apresentados nas colunas 1 , 2, 5 e 6, corroboram as hipóteses deste estudo e os resultados de diversos trabalhos internacionais (Wakelin, 1998; Sterlacchini, 1999; Correa et al., 2007; Kumar; Siddarthan, 1994). Em ambas as regiões, encontrou-se o mesmo padrão de relação entre as variáveis independentes e a propensão a exportar. Destaca-se que a probabilidade de exportar relaciona-se positivamente com tamanho, idade, presença de capital estrangeiro, certificação de

4 Para a realização deste estudo empírico foi utilizado o software Stata 11. Todas as estimações foram realizadas utilizando o comando robust, para correção de qualquer tipo de heterocedasticidade.

5 O número de observações se altera entre os modelos, pois cada um se utiliza de um conjunto diferente de variáveis, e por isso conta com um número distinto de empresas respondentes do questionário. 
qualidade, realização de treinamento e uso de insumos importados, com coeficientes associados positivos e estatisticamente significativos. Deve-se ressaltar ainda que a variável pessoal ocupado ao quadrado apresenta coeficiente associado negativo e estatisticamente significativo, indicando que a relação entre tamanho e exportação é não-linear (U invertido), como já apontava Wakelin (1998).

Estudos internacionais como o de Sjoholm (2003) e o de Correa et al. (2007) também encontram evidências que o uso de insumos importados afeta a probabilidade das empresas exportarem. A justificativa para esse resultado se deve ao fato de os insumos importados serem considerados canais por meio dos quais as empresas estabelecem relacionamento com o mercado externo. Assim, a importação de produtos intermediários pode ser um importante determinante da probabilidade da empresa exportar.

Quanto ao primeiro indicador de inovação (Inova) (colunas 1 e 5), em ambas as amostras, o coeficiente associado é positivo e estatisticamente significativo a $1 \%$, indicando que desenvolver novos produtos afeta positivamente a probabilidade das empresas exportarem. Esse mesmo resultado foi encontrado por Fagerberg (1988a) e Belaney e Wakelin (2002).

Quanto ao segundo indicador de inovação (Intensidade Inova), os resultados apresentados nas colunas 2 e 6 apontam que na amostra da América Latina o coeficiente associado é negativo e não é estatisticamente significativo; enquanto que para a amostra da Europa do Leste, o coeficiente associado é positivo e estatisticamente significativo, evidenciando que quanto maior o número de novos produtos lançados, maior a probabilidade da empresa exportar.

Ainda na Tabela 7, as colunas 3, 4, 7 e 8 apresentam os resultados das estimações dos modelos probabilísticos com uso de variável instrumental com intuito de corrigir o problema de endogeneidade entre inovação e exportação. Os resultados apresentados na coluna 3 e 7 referem-se às estimações do modelo probabilístico com variável endógena contínua (Intensidade Inova), o modelo IV Probit; e os resultados da coluna 4 e 8 sistematizam os resultados das estimações dos modelos probabilísticos com variável endógena binária (Inova), o modelo Bi Probit. Tanto para a variável Intensidade Inova quanto para a variável Inova foi utilizada a variável gasto em $\mathrm{P} \& \mathrm{D}$ como variável instrumental. $\mathrm{O}$ gasto em $\mathrm{P} \& \mathrm{D}$ é considerado na literatura um indicador de esforço inovativo, influenciando o desempenho inovativo da empresa, medido pelo número de novos produtos. Por 
se tratar de um esforço realizado no início do processo de inovação, com acentuado risco e incerteza, o gasto em $\mathrm{P} \& \mathrm{D}$ não influencia diretamente $\mathrm{o}$ desempenho exportador. Sendo assim, o gasto em $\mathrm{P} \& \mathrm{D}$ pode ser utilizado como uma variável instrumental por estar relacionado com a variável inovação e não estar relacionado diretamente com a variável exportação (Ganotakis; Love, 2011).

Nos modelos IV Probit (colunas 3 e 7), a variável dependente é binária, assumindo valor 1 se a empresa exporta e valor 0 se a empresa não exporta, e as variáveis independentes são as mesmas do modelo probit. Nos modelos IV Probit, o teste Wald de exogeneidade é estatisticamente significativo apenas para a amostra de países da América Latina, denotando a existência de endogeneidade entre as variáveis inovação e exportação. Contudo, para as empresas dos países da Europa do Leste, o resultado do teste Wald indica que a hipótese nula de exogeneidade não é rejeitada, sendo o modelo probit padrão o mais apropriado para analisar a relação entre inovação e exportação para os países desta região. Deste modo, a análise que segue centra-se nas estimações para a América Latina. Os resultados indicam que tamanho, idade, presença de capital estrangeiro e certificação de qualidade apresentam coeficientes associados positivos e estatisticamente significativos entre 1 e $5 \%$. Tal resultado significa que tal conjunto de variáveis afeta positivamente a probabilidade das empresas exportarem, apresentando comportamento semelhante ao modelo probabilístico estimado, inicialmente, sem controle de endogeneidade.

O resultado encontrado para a variável certificação de qualidade coincide com diversos estudos internacionais que consideram essa variável uma proxy de qualidade dos produtos, apresentando relação positiva com a probabilidade da empresa se inserir no mercado externo com mais competitividade (Correa et al., 2007).

Quanto ao comportamento das variáveis de inovação, que constituem o principal objetivo deste estudo, observa-se que os resultados são positivos e estatisticamente significativos. $\mathrm{Na}$ coluna 3 , os resultados do IV Probit apontam que, corrigindo a endogeneidade com uso de variável instrumental (PeD), o coeficiente associado à variável Intensidade Inova é positivo e estatisticamente significativo, indicando que as empresas que desenvolvem mais novos produtos têm maior probabilidade de exportar.

Nas colunas 4 e 8 estão descritos os resultados das duas equações das estimações do modelo Bi Probit. Na primeira equação, a variável dependente 
é binária, assumindo valor 1 se a empresa inova e valor 0 se a empresa não inova. A variável independente é gasto em $\mathrm{P} \& \mathrm{D}$, que assume valor 1 se a empresa realiza alguma atividade de $\mathrm{P} \& \mathrm{D}$ e valor 0 caso contrário. $\mathrm{Na}$ segunda equação, a variável dependente é binária, assumindo valor 1 se a empresa exporta, e valor 0 se a empresa não exporta. As variáveis independentes são as mesmas dos modelos probabilísticos anteriores. Os resultados apresentados nas equações (b) indicam que tamanho, idade, presença de capital estrangeiro e certificação de qualidade apresentam coeficientes associados positivos e estatisticamente significativos a $1 \%$, assemelhando-se aos resultados obtidos nas estimações dos modelos IV Probit. Pelos resultados apresentados nas equações (a), a variável instrumental $\mathrm{P} \& \mathrm{D}$ afeta diretamente a decisão de inovar das empresas das duas amostras. Já as equações (b) sugerem que a decisão de inovar afeta a probabilidade de exportar, pois apresenta coeficientes associados positivos e estatisticamente significativos. Os testes Wald para ambas as regiões indicam que as equações de inovação e exportação devem ser estimadas conjuntamente em um modelo Bi Probit, pois a hipótese nula de exogeneidade é rejeitada.

A Tabela $8^{6}$ apresenta os resultados dos modelos de seleção de Heckman para as mesmas regiões com o intuito de corrigir o problema de viés de seleção e evidenciar se a inovação influencia a intensidade de exportação das empresas. Essa hipótese é fundamental, pois, como visto na seção 2, diversos trabalhos apontam para a existência de autosseleção das empresas, ou seja, são as melhores firmas que se tornam exportadoras. A primeira equação (equação de seleção) analisa, através de um modelo probabilístico, a decisão da empresa exportar. Como anteriormente, a variável dependente é binária. E as variáveis independentes são as mesmas dos modelos anteriores. Os indicadores de inovação são: inova (colunas 1 e 5) ou intensidade inova (colunas 3 e 7).

$\mathrm{Na}$ segunda equação (equação de resultado) busca-se compreender as variáveis determinantes da intensidade de exportação das empresas. A variável dependente é contínua, intensidade da exportação. Os indicadores de inovação são os mesmos, ou seja, inova (colunas 2 e 6) ou intensidade inova (colunas 4 e 8).

De acordo com Wooldridge (2010), para uma correta especificação desse

6 O número de observações se altera entre os modelos, pois cada um se utiliza de um conjunto diferente de variáveis, e por isso conta com um número distinto de empresas respondentes do questionário. 
modelo, deve-se inserir na equação de seleção uma variável que explique a probabilidade da empresa exportar, mas que não tenha impacto sobre a variável dependente da equação de resultado (intensidade da exportação). Para o estudo proposto, a variável certificação de qualidade foi selecionada por atender a esse critério, já que possuir um selo de qualidade influencia a decisão de exportar da empresa, contudo, não se relaciona diretamente com a intensidade da exportação. O coeficiente de correlação $(\rho)$ entre o termo de erro da equação de probabilidade de exportar $\left(e_{i}\right)$ e o termo de erro da equação de intensidade de exportação $\left(u_{i}\right)$ deve ser significativamente diferente de zero, como mostra o teste de Wald para independência dos modelos $(\rho=0)$. Para a amostra da América Latina, os resultados confirmam a hipótese de que ambas as decisões tomadas pelas empresas (exportar e o percentual das vendas advindas das exportações) são interdependentes. No entanto, no caso da Europa do Leste, não parece haver dependência entre as equações, o que indica que o modelo de Heckman para controle de viés de seleção não é adequado. Portanto, a análise que segue se restringe ao caso da América Latina.

Os resultados dos modelos estimados com controle de viés de seleção mostram resultados bem distintos dos obtidos com os demais modelos. Com relação às variáveis relativas a características e capacitação das firmas, os resultados não diferem muito. Verifica-se, com base nas equações de seleção, que tamanho, idade, presença de capital estrangeiro, certificado de qualidade, treinamento e uso de insumos importados aumentam a probabilidade das empresas exportarem.

Sempre no caso da América Latina, controlando-se o viés de seleção, o capital estrangeiro afeta positivamente a intensidade das exportações. As demais variáveis apresentam comportamentos distintos em cada modelo. Os estudos internacionais encontram evidências pouco conclusivas sobre a relação entre idade e exportação. Os resultados de Smith et al. (2002) apontam para uma relação positiva entre essas variáveis. Sjoholm (2003) e Wignaraja (2011), por sua vez, encontram uma relação negativa entre idade e exportação. $\bigcirc$ autor argumenta que uma possível justificativa para essa relação negativa deve-se ao fato de que se as empresas novas forem intensivas em inovação, elas podem apresentar mais vantagens para entrar no mercado externo do que as empresas mais antigas.

Contudo, as estimações indicam conclusões muito diferentes quando se trata das variáveis de inovação. 


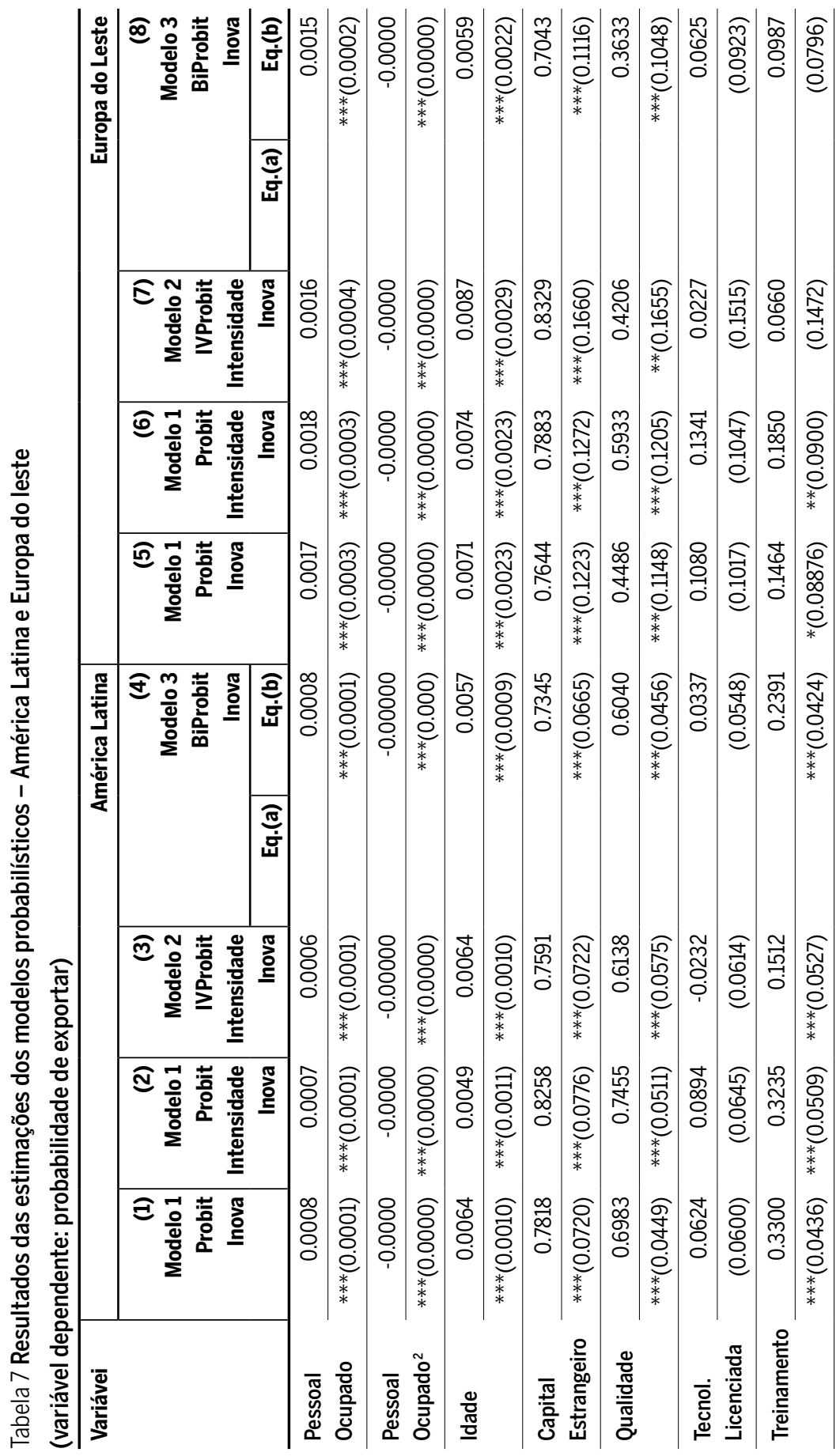




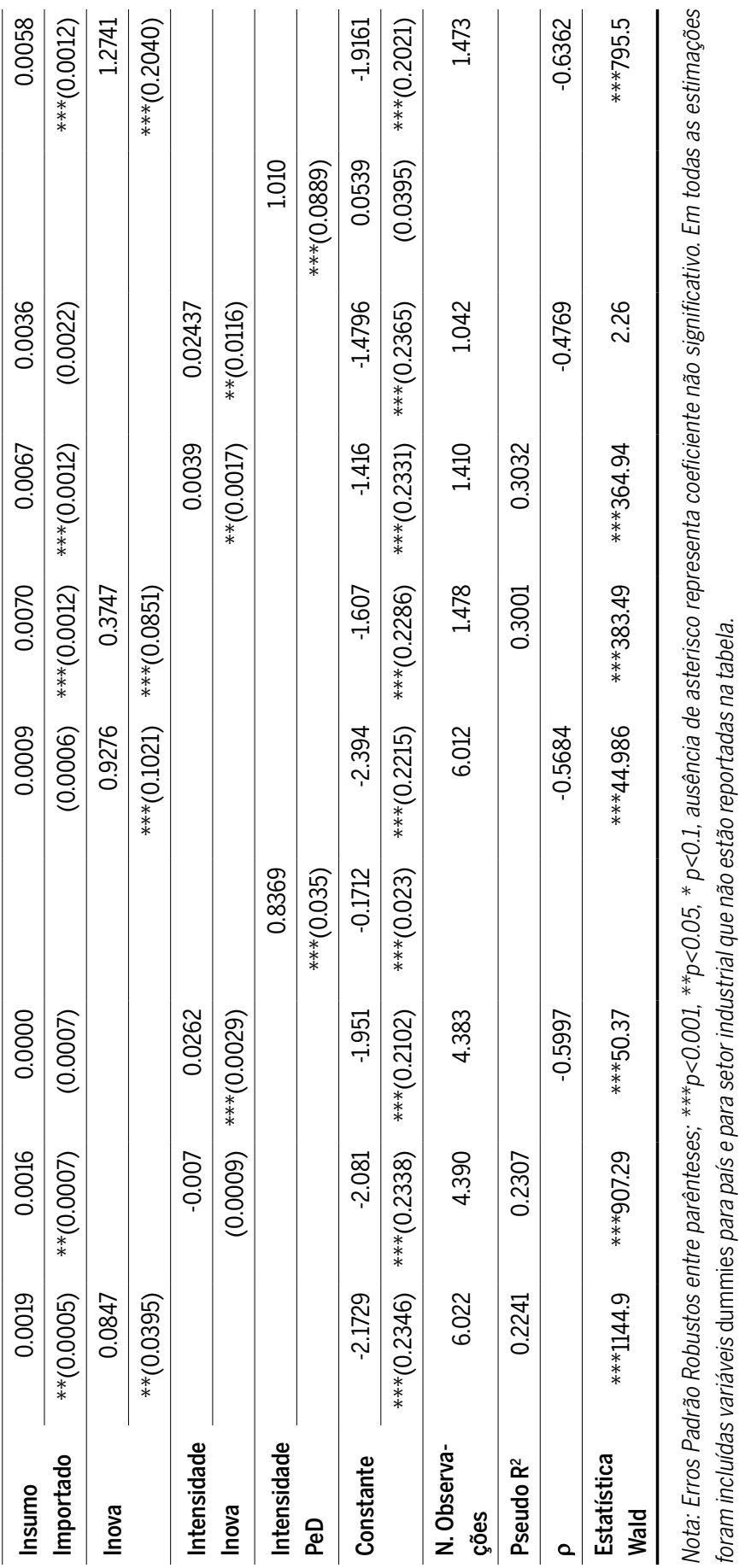




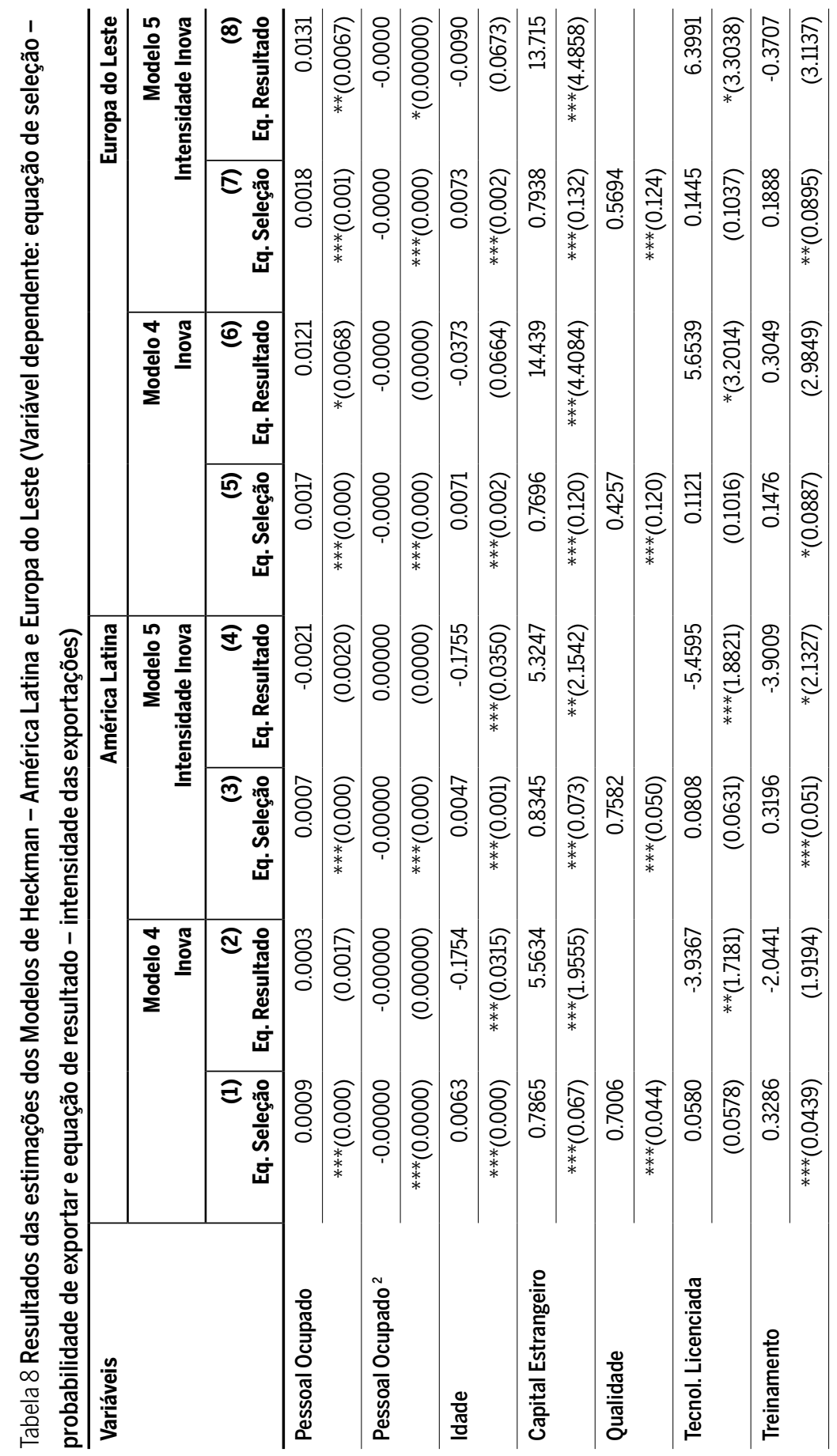




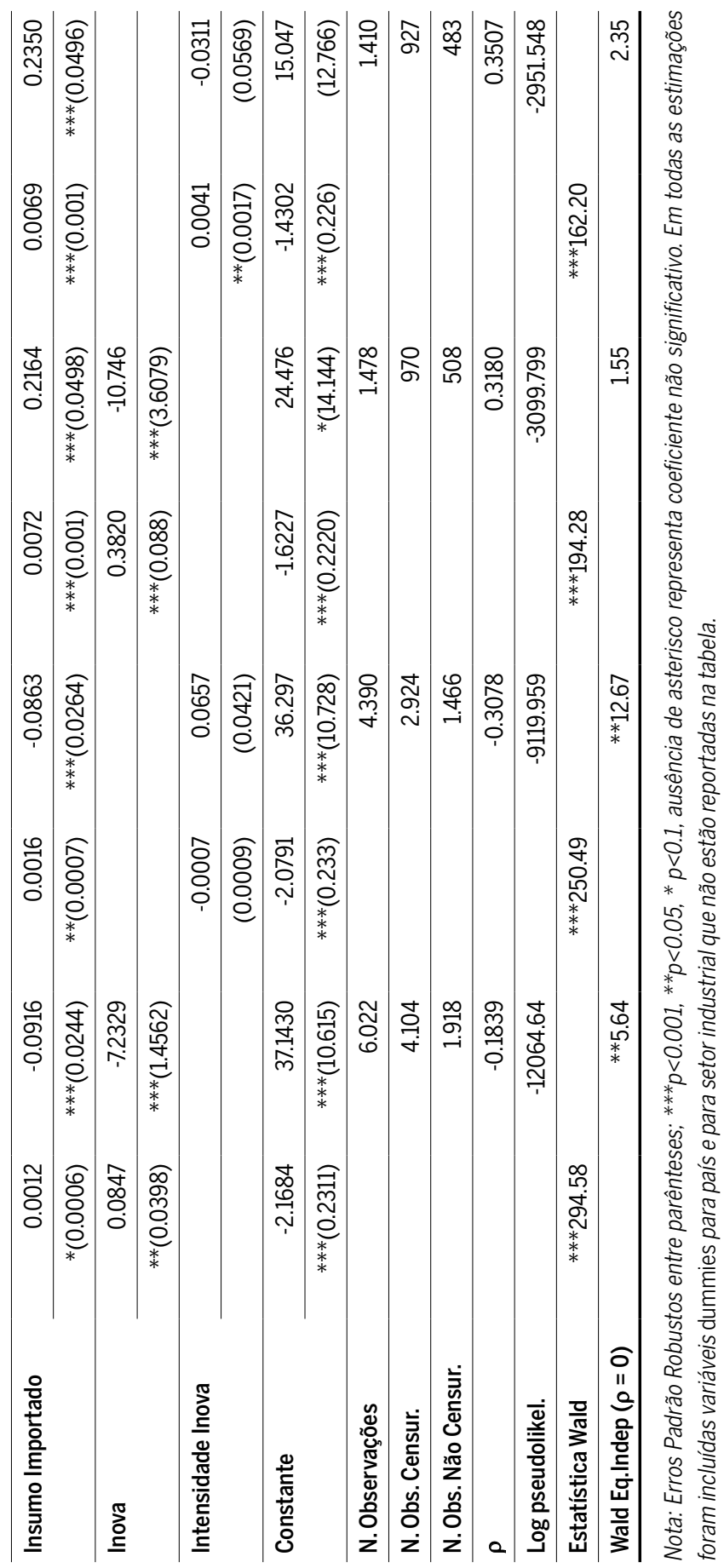


Para os países da América Latina, os resultados indicam que a inovação afeta a probabilidade das empresas exportarem (equação de seleção). No entanto, o seu impacto sobre a intensidade das exportações, quando se controla o viés de seleção, é negativo e significativo. Ou seja, os resultados sugerem que o fato de a firma inovar aumenta a sua probabilidade de se tornar exportadora, mas, uma vez que ela exporta, o aumento do esforço inovativo (número de novos produtos) reduz as exportações, o que não seria esperado. Utilizando-se a variável intensidade inova, os resultados indicam que essa variável nem afeta a probabilidade da empresa se tornar exportadora, nem que a intensidade das exportações seja influenciada por ela dado que seja exportadora. Vale ressaltar que no modelo probabilístico (modelo 1, coluna 2) a variável intensidade inova também não afeta a probabilidade de exportar. Essa variável influencia a probabilidade de exportar somente após o controle da endogeneidade com o uso do IV Probit (modelo 2).

Seria de se esperar que a inovação afetasse ao menos a probabilidade de a firma exportar, o que é verificado pelo modelo 1. Mas não era esperado que seu impacto fosse negativo, dado que a firma se tornou exportadora, ou então que não tenha impacto nem ao menos sobre a probabilidade de a firma ser exportadora (modelo 2). Uma hipótese que pode ser avançada baseia-se no fato de, sendo empresas sediadas na América Latina, com baixo percentual de firmas com capital estrangeiro, visarem primordialmente o mercado doméstico. $O$ percentual de empresas que declaram serem inovadoras é relativamente alto (Tabela 5), mas o percentual relativo à intensidade de inovação é baixo (Tabela 4). São firmas baseadas predominantemente em setores de baixa e média intensidade tecnológica, em que a inovação não é um fator tão essencial para permitir acesso ao mercado externo. Os dados da Tabela 3, por exemplo, evidenciam que, para a América Latina, apenas $1.8 \%$ das firmas são do setor de eletrônicos e $7.5 \%$ de máquinas e equipamentos. Portanto, para muitas firmas, o nexo entre inovação e exportação seria tênue.

Outra explicação pode residir no fato de as firmas não avaliarem corretamente, em muitos casos, o que é inovação. Poderia haver um número excessivo de firmas que informam terem realizado algum tipo de inovação quando a realidade é inferior, distorcendo os resultados. De toda forma, a conclusão que emerge é que o efeito da inovação sobre as exportações, ao se controlar o viés de seleção, é insignificante ou negativo. 


\section{Conclusões}

A inovação vem sendo tratada, nas últimas décadas, como um dos principais motores do crescimento do comércio exterior. Um grande conjunto de estudos vem se desenvolvendo com objetivo de encontrar evidências empíricas sobre a relação entre inovação e exportação.

A partir da análise do perfil das empresas da América Latina e Europa do Leste, pode-se verificar que a maioria das empresas em ambas as regiões é constituída por não exportadoras, ainda que a participação das exportadoras seja elevada (52.8\% na América Latina e 38\% na Europa do Leste). Quanto às especificidades regionais, as empresas da América Latina são mais velhas, têm menor intensidade de exportação e de inovação apesar de apresentarem idêntica intensidade de $\mathrm{P} \& \mathrm{D}$ em comparação com as empresas da Europa do Leste. Apresentam tamanhos semelhantes, mas possuem menor qualificação de pessoal, bem como menor percentual de pessoal ocupado com treinamento, em relação às empresas da Europa do Leste.

No que tange ao perfil das exportadoras em relação às não exportadoras, verifica-se que há um predomínio das grandes empresas entre as exportadoras e de pequenas empresas entre as não exportadoras. Pode-se afirmar que as exportadoras são mais velhas, são mais intensas em $\mathrm{P} \& \mathrm{D}$ e no desenvolvimento de novos produtos (Intensidade Inovação), são maiores, possuem um percentual do pessoal ocupado com treinamento superior às não exportadoras, fazem uso de um maior percentual de insumos importados e apresentam uma maior utilização de capacidade instalada.

O exercício empírico deste trabalho tenta avançar no debate sobre exportação e inovação no nível da firma, pois corrige os problemas de endogeneidade e de viés de seleção, e inova em considerar a interdependência entre a decisão de exportar e a intensidade da exportação em relação às vendas das empresas. Além disso, talvez seja o primeiro a utilizar uma amostra relativamente grande de firmas para um conjunto bastante amplo de países.

As evidências encontradas pelas estimações dos modelos probabilísticos sugerem que existe um padrão entre as empresas da América Latina e Europa do Leste, sendo que tamanho, idade e participação de capital estrangeiro influenciam positivamente na decisão de exportar das empresas. Quanto aos indicadores de inovação, os resultados dos modelos probabilísticos de ambas as regiões apontam que a inovação afeta positivamente a probabilidade de exportação das empresas. 
Ao se controlar o viés de seleção, no entanto, os resultados se alteram dramaticamente. No caso das empresas da Europa do Leste, as regressões indicam não haver viés, o que sugere que os resultados anteriores são os melhores. Já para as empresas da América Latina, onde há viés de seleção, esse controle mostra que o resultado da inovação ou tem efeito negativo sobre as exportações ou seu efeito é desprezível. As causas para esse resultado não são muito claras, mas é possível que pelo fato de serem empresas predominantemente de setores de baixa intensidade tecnológica, a inovação tem baixo poder de influenciar as exportações.

De toda forma, os resultados dão suporte à ideia de que o esforço de inovação é crucial para o maior dinamismo das exportações. Países que ampliaram o conteúdo de conhecimento nas suas economias certamente tiveram melhor desempenho do seu comércio externo. A lição que fica é que os países emergentes devem aumentar seus esforços, seja para aumentar os gastos em $\mathrm{P} \& \mathrm{D}$, seja para melhorar o nível de qualificação de mão de obra, não apenas para obter maior dinamismo de suas exportações, mas também para, principalmente, melhorar a competitividade geral da economia.

\section{Referências}

AMABLE, Bruno; VERSPAGEN, Bart. The Role of Technology in Market Shares Dynamics. Applied Economics, vol. 27, p. 197-204, 1995.

ANDERSON, Martin; LÖÖF, Hans. Learning by Exporting Revisited: The Role of Intensity and Persistence. Scandinavian Journal of Economics, vol. 111, n. 4, p. 893-916, 2009.

AW, Bee Yan; ROBERTS, Mark; WINSTON, Tor. Export Market Participation, Investments in $\mathrm{R} \& \mathrm{D}$ and Worker Training and the Evolution of Firm Productivity. The World Economy, vol.14, n.1, p. 83-104, 2007.

AW, Bee Yan; ROBERTS, Mark; WINSTON, Tor. R\&D Investments, Exporting and the Evolution of Firm Productivity. American Economic Review, Papers and Proceedings, vol. 98, n. 2, p. 451-456, 2008.

AW, Bee Yan; ROBERTS, Mark; XU, Daniel Yi. R\&D Investments, Exporting and Productivity Dynamics. NBER Working Papers Series 14670, January, 2009.

BANCO MUNDIAL. Enterprise Surveys. Disponível em: <http://www.enterprisesurveys. org >. Acesso em 16 de outubro de 2011.

BEISE-ZEE, Rian; RAMMER, Christian. Local User-producer Interaction and Export Performance of Firms. Small Business Economics, vol. 27, p. 207-222, 2006.

BERNARD, Andrew B.; JENSEN, J. Bradford. Exceptional Exporter Performance: Cause, 
Effect, or Both? Journal of International Economics, vol. 47, p. 1-25,1999.

BERNARD, Andrew B.; JENSEN, J. Bradford. Exporters, Jobs and Wages in US Manufacturing: 1976-1987. Brookings Papers on Economic Activity, Microeconomics, p. 67-112, p. 1995.

BERNARD, Andrew B.; JENSEN, J. Bradford. Why Some Firms Export. Review of Economics and Statistics, vol. 86, n. 2, May, p. 561-569, 2004.

BLEANEY, Michael; WAKELIN, Katharine. Efficiency, innovation and exports. Oxford Bulletin of Economics and Statistics, 64, 3, 2002.

CAMERON, A. Colin; TRIVEDI, Pravin K. Microeconomics Using Stata. Stata Press Publication, 2010.

CLERIDES, Sofronis; LACH, Saul; TYBOUT, James. Is Learning by Exporting Important? Micro-Dynamic Evidence from Colombia, Mexico and Morocco. Quarterly Journal of Economics, vol. 113, n. 3, August, p. 903-47, 1998.

CORREA, Paulo; DAYOUB, Mariam; FRANCISCO, Manuela. Identifying Supply-Side Constraints to Export Performance in Ecuador: An Exercise with Investment Climate Survey Data. World Bank Policy Research Working Paper, n. 4179, March, 2007.

DAMIJAN, Joze; KOSTEVC, Crt. Learning by Exporting: Continuous productivity Improvements or Capacity Utilization Effects? Evidence from Slovenian Firms. Review of World Economics, vol. 142, n. 3, p. 600-614, 2006.

FAGERBERG, Jan. International Competitiveness. The Economic Journal, vol. 98, n. 391, June, p. 355-374, 1988a.

FAGERBERG, J. Why Growth Rates Differ? In: DOSI, G.; FREEMAN, C.; NELSON, R.; SILVERBERG, G.; SOETE, L. (Eds). Technical Change and Economic Theory. Pinter: London and Columbia University Press. New York, 1988 b.

GANOTAKIS, Panagiotis; LOVE, James. R\&D, Product Innovation and Exporting: Evidence from UK New Technology Firms. Oxford Economic Papers, vol. 63, n. 2, April, 2011.

GIRMA, Sourafel; GÖRG, Holger; HANLEY, Aoife. R\&D and Exporting: A Comparison of British and Irish Firms. Review of World Economics, vol. 144, n. 4, p. 750-773, 2008.

GREENAWAY, David; KNELLER, Richard. Industry Differences in the Effect of Export Market Entry: Learning by Exporting? Review of World Economics, vol. 143, n. 3, p. 416-432, 2007.

GREENHALGH, Christine. Innovation and Trade Performance in the United Kingdom. The Economic Journal, vol. 100, n. 400, Conference Papers, p. 105-118, 1990.

HARRIS, Richard; LI, Qian Cher. Exporting, R\&D and Absorptive Capacity in UK Establishments. Oxford Economic Papers, vol. 61, n. 1, p. 74-103, 2009.

HECKMAN, James J. Sample Selection Bias as a Specification Error. Econometrica, vol. 47, n. 1, January, p. 153-61, 1979.

KIM, Soo-Il; GOPINAT, Munisamy; KIM, Hanho. High Productivity Before or After Exports? An Empirical Analysis of Korean Manufacturing Firms. Journal of Asian Economics, vol. 20, p. 410-418, 2009.

KRUGMAN, Paul. A Model of Innovation, Technology Transfer and the World Distribution of Income. Journal of Political Economy, vol. 87, p. 253-266, 1979. 
KUMAR, Nagesh; SIDDARTHAN, N. S. Technology, Firm Size and Export Behaviour in Developing Countries: the case of Indian Enterprises. The Journal of Development Studies, 31, 2, p. 289-309, 1994.

LACHENMAIER, Stefan; WOESSMANN, Ludger. Does Innovation Cause Exports? Evidence from Exogenous Innovation Impulses and Obstacles Using German Micro Data. Oxford Economic Papers, vol. 58, n. 2, April, p. 317-350, 2006.

LIU, Xiahui; BUCK, Trevor. Innovation Performance and Channels for International Technology Spillovers: Evidence from Chinese High-Tech Industries. Research Policy, vol. 36, p. 355-366, 2007.

MARTINS, Pedro; YANG, Yong. The Impact of Exporting on Firm Productivity: a Meta-analysis of the Learning by Exporting Hypothesis. Review of World Economics, vol. 145, p. 431-445, 2009.

MISSIO, F.; GABRIEL, L. Sistema Nacional de Inovação em um Modelo com Restrição Externa. In: Anais do 42 Encontro Nacional de Economia, Natal - RN, 2014.

OECD. Science, Technology and Competitiveness, Committee for Scientific and Technological Policy, SPT (80)19, OECD, Paris, 1980.

PAVITT, Keith; SOETE, Luc. Innovative Activities and Export Shares: Some Comparisons Between Countries and Industries. In: PAVITT, Keith (Ed.) Technical Innovation and British Economic Performance. Mac Millan, London, 1980.

POSNER, Michael. International Trade and Technical Change, Oxford Economic Papers, vol. 13, p. 323-341, 1961.

SANYAL, Prabuddha. The Role of innovation and Opportunity in Bilateral OECD Trade Performance. Review of World Economics, vol. 140 (4), p. 634-664, 2004.

SJOHOLM, Fredrik. Which Indonesian firms export? The importance of foreign networks. Paper in Regional Sciences 82, p. 333-350, 2003.

SMITH, Valdemar; MADSEN, Erik S.; DILLING-HANSEN, Mogens. Export performance and investiment in R\&D. The Danish Institute for Studies in Research and Research Policy, Working Paper n. 04, 2002.

SOETE, Luc. A General Test of Technological Gap Trade Theory. Weltwirtschaftliches Archiv, vol. 117, Heft 4, p. 638-660, 1981.

STERLACCHINI, Alessandro. Do innovative activities matter to small firms in non-R\&D intensive industries? An application to export performance. Research Policy, 28, p. 819832, 1999.

TROFIMENKO, Natalia. Learning by Exporting: Does it Matter Where One Learns? Evidence from Colombian Manufacturing Firms. Economic Development and Cultural Change, vol. 56, n. 4, July, p. 871-894, 2008.

VERNON, Raymond. International Investment and International Trade in the Product Cycle. Quarterly Journal of Economics, May, 1966.

WAKELIN, Katharine. The Role of Innovation in Bilateral OECD Performance. Applied Economics, vol. 30, p. 1335-1346, 1998.

WIGNARAJA, Ganeshan. Innovation, learning, and exporting in China: Does R\&D or a tech- 
nology index matter? Journal of Asian Economics, 2011.

WOOLDRIDGE, Jeffrey M. Econometric Analysis of Cross Section and Panel Data. The MIT Press, Cambridge, Massachusetts, 2010.

\section{Sobre os autores}

Marcelo JoséBraga Nonnenberg - marcelo.nonnenberg@ipea.gov.br Economista do IPEA e professor da PUC-RIO, Rio de Janeiro.

Ana Paula Macedo de Avellar - anaavellar@ufu.br

Professora Associada do Instituto de Economia e Relações Internacionais da Universidade Federal de Uberlândia. Bolsista Produtividade em Pesquisa - CNPq.

Os autores agradecem o apoio do IPEA, FAPEMIG e CNPq.

\section{Sobre o artigo}

Recebido em 29 de abril de 2016. Aprovado em 16 de agosto de 2016. 